\title{
A Literature Review on Regional Decentralization in China Jusheng Yang
}

\author{
School of Management, Lanzhou University, Lanzhou 730000, China; \\ yangjsh15@Izu.edu.cn
}

Keywords: Centralization, Decentralization, Regional Decentralization in china.

\begin{abstract}
.
Chinese decentralization has had a significant impact on the country's political and economic life. The rapid economic growth in the past 30 years in China has been inextricably linked with the pattern of decentralization. However, the particularities of such political centralization and fiscal decentralization have also led to many problems and contradictory. This paper analyzes the relationship between fiscal decentralization and social development from the perspectives of fiscal revenue and expenditure, economic development and government control. It concludes that there are mainly two major contradictions in Chinese decentralization at present, namely, conflicts between the distribution of financial rights and powers and the contradiction between interests of the promotion mechanism of officials with GDP as the core indicator, which hopefully will provide a new research paradigm for the decentralization of China.
\end{abstract}

\section{Introduction}

The main manifestation of Chinese decentralization is "fiscal decentralization" and "administrative decentralization." "Administrative decentralization" is mainly the management and development of social and economic affairs within the jurisdiction by local governments at all levels, and enjoys a high degree of autonomy especially in the setting and implementation of regulations. The "fiscal decentralization" is mainly carried out by the Central Government and is almost completely confined to defense diplomacy and maintain the central government and its functional departments, the provision of domestic public goods and services is almost entirely undertaken by local finance. It is worth noting that Chinese-style decentralization has always been inseparable from "political centralization.". Xu Chenggang (2011) referred to this system as "economic decentralization under political centralization," or "regional decentralized authoritarian system," and pointedly pointed out the miracle of economic growth in China during the reform period and the numerous serious social problems such as environmental pollution and the disparity between the rich and the poor attributed systematically to this Chinese decentralization system.

In 1994, the tax-sharing reform practiced in China can be regarded as the "redistribution of economic power" in China. Before the reform of the tax-sharing system, the Chinese government has been implementing a fiscal system that properly divides its revenue among all levels of government. In fact, it can be seen as finding the highest profit point in the two extremes of fiscal freedom and fiscal control. In 1950, China implemented a short time of "unified revenue and expenditure." In 1994, China implemented a system of tax-sharing reform that mainly provided detailed institutional provisions on matters of power, taxation and management. It clearly defined the scope of central and local government expenditures, the scope of revenues of the central and local governments, and the tax revenues of central and local tax authorities, which fully mobilized the enthusiasm of the central and local governments. It can be seen from above that the share of fiscal power in the distribution of central and local governments and the impetus of political centralization to the decentralization of power are important factors that affect economic development.

In "The Measurement of Financial Decentralization Theory and the Empirical Analysis of China in 1985-2007" written by Xu Yongsheng (2012), the paper divides the fiscal decentralization into three categories: fiscal decentralization index based on expenditure, income, and weighted local autonomy; 
in the article of "Chinese-style fiscal decentralization measures the amount of" published by Gong Feng (2012), it mentioned that there are three indicators of decentralization to income, expenditure and fiscal autonomy. At the same time, it is considered that no index is optimal, and the corresponding indicators should be selected according to the time period of the research sample. Therefore, studying the revenue and expenditure of the government is a breakthrough point for studying fiscal decentralization. In the following section, we will review the literature on fiscal decentralization and fiscal revenue and expenditure, economic development and government regulation in the following sections. Figure 1 shows the general framework.

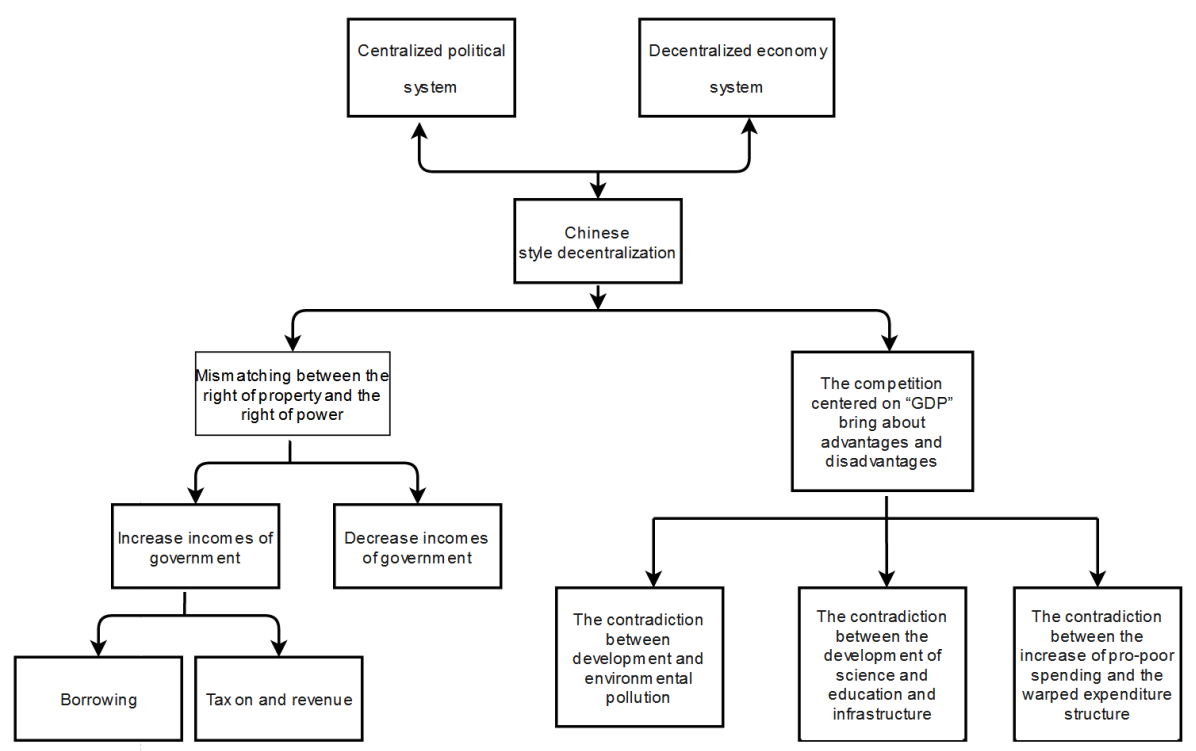

Figure 1 Chinese decentralized research framework

\section{Fiscal Decentralization and Financial Revenue and Expenditure}

At present, the fiscal decentralization in China shows a clear "decentralization of responsibility, collection of fiscal power", which directly leads to the mismatch between financial power and routine power. Local governments need to achieve the performance targets stipulated by higher level governments with limited financial resources, and also develop local specialties according to local conditions. In order to balance financial and routine rights, many governments have only resorted to increasing extra-budgetary income and borrowing to increase their sources of income. In the meantime, under the encouragement of "officials promoted to championship" under the political centralization, in order to better stimulate local economic development, the structure of local fiscal expenditure has also been distorted.

\subsection{Income behavior}

Li Wan (2010), mentioned in her ariticle "Chinese-style fiscal decentralization and local government extra-budgetary revenue inflation research" that when local governments lack the budgetary autonomy, the local government revenue can not be obtained by way of tax levy. This has prompted local governments to divert funds from the budget to extr-abudgetary sources or direct extra extrabudgetary income. In fact, there are many kinds of extra-budgetary government revenue, such as industrial and commercial tax surcharges, local reorganization and renovation of capital income, public housing rental income, etc., and land finance has more profit-making space than any other, so land finance has become the main source of government extra-budgetary income. In his article entitled "Fiscal Decentralization - Local Government Competition and Land Finance" by Wu Qun (2010), it clearly states that land finance has gradually become the "second finance" of local governments after the tax-sharing reform. Local governments are mainly responsible for increasing 
their extra-budgetary revenues by attracting FDI from foreign direct investment. Sun Jianfei (2014) also mentioned in the article of "Financial Decentralization, Land Finance and Urban Expansion in China - An Empirical Analysis Based on Simultaneous Equations Metrology Model" that through land financing, local governments conduct the infrastructure construction and urban expansion to form the development model of "fiscal decentralization-land financing-urban expansion", and concluded that the impact of fiscal decentralization on the scale of land financing is positive and so is the impact of land financing scale on urban expansion.

In addition, borrowing is also an important means for the government to increase its extra-budgetary income. In Chen Jing's article entitled "Fiscal Decentralization, Promotion Incentives and Local Government Debt - Empirical Evidence from Provincial Panels Based on the Perspective of City, Town and Investment Bonds", it clearly pointed out that in the face of fiscal deficits and political pressure, the government often solves the problems by increasing extra-budgetary amounts and borrowing and other measures. The size of the amount of debt will be affected by the degree of fiscal decentralization and competition mechanism of officials. From the perspective of enterprises to analyze the government's financial resources, the tax burden imposed by the government on enterprises and government subsidies will directly affect the government's revenue and expenditure, and it is also an important means for the government to directly intervene in the enterprises.

\subsection{Expenditure behavior}

The mainstream fiscal decentralization theory generally believes that the two mechanisms of "vote by hand" and "vote by feet" can optimize the expenditure behavior of local governments and improve the efficiency of local public goods supply. But in Chinese decentralization, in general, the scholars found that fiscal decentralization can improve the production expenditure of local government, such as the city infrastructure, but inhibited the non productive expenditure, such as education and health expenditure.

In terms of urban infrastructure, Tang Yugang and Chen Jiang (2012) pointed out that the establishment of fiscal decentralization system and the launching of land element marketization reform contributed to the acceleration of China's urban infrastructure in the late 1990s. Under the fiscal decentralization, local officials' preference for infrastructure investment stems from the improvement of infrastructure, which helps to attract investment and achieve faster economic growth and performance improvement. This means that the competition between jurisdictions generated by the decentralized economic governance model increases the investment demand for infrastructure. On the other hand, the land finance model improves the ability of local governments to supply infrastructure. These two factors jointly drive the rapid increase in the stock of infrastructure in China. In China's local compulsory education and health services, Gong Feng and Lu Hongyou (2013) found that for compulsory education, the higher the proportion of local government financial transfer from the central transfer payment is, the higher the local government's financial funds and the higher the fiscal expenditure, which helps to improve the efficiency of local compulsory education service allocation; however, for the medical treatment, local governments have more access to and allocate financial resources, whether they come from central government transfer payments or from local governments own income, which will have a negative impact on the allocation efficiency of local health services. The differences in the information advantages that local governments have over compulsory education and health care services and the differences in the transfer payment arrangements between the central government and the two service sectors may be the important reasons for these gaps. Li Qiyun and Liu Xiaoyong (2010) also found that fiscal decentralization has exacerbated the inter-regional per capita budget expenditure on health and the gap in the number of hospital beds owned by 10,000 people. However, Qiao Baoyun et al. (2005) and Fu Yong (2010) found that fiscal decentralization did not increase the effective supply of compulsory primary education. The main reason for this is that the barrier of population mobility and its regional differences lead to the shift of local government behaviors toward the pursuit of capital investment and economic growth rate, leading to fierce financial competition in various regions and correspondingly exacerbating the financial expenditure on the nature of quasi public goods with 
strong externalities such as compulsory education. The above conclusion has also been supported by Fan Yunqi (2010). He believes that the dual incentive structure of local governments under economic decentralization and administrative concentration makes the local governments not only consider the opinions of local masses, but also the interests of higher-level governments, thus the local government is the agent of the superior government and the local people. Therefore, the author constructs a multitasking principal-agent model under Chinese decentralization, and draws a conclusion that the expenditure of science, culture, health and education is negatively correlated with the degree of decentralization of local governments through data analysis, while the result of infrastructure is contradictory.

\section{Financial Decentralization and Economic Development}

In addition to affecting fiscal revenue and expenditure in countries and regions, fiscal decentralization will also have a positive or negative impact on the economic development of human society. In his article "China's fiscal decentralization and regional economic growth," Shen Kunrong (2005) argued that institutional arrangements for fiscal decentralization can mobilize the enthusiasm of local governments in economic development. Therefore, fiscal decentralization in general helps to promote economic growth.

Combined with the historical reality of China's once highly fiscal centralized state, the local government is given greater autonomy in the investment and construction of public products, which to some extent decentralizes decision-making and enhances economic efficiency. In the article of "Fiscal Decentralization, Economic Growth and Fluctuation," Zhou Yean (2008) focused on explaining that while fiscal decentralization promotes economic growth, it also triggers economic fluctuations. The impact of fixed asset investment and foreign direct investment under the fiscal decentralization on economic fluctuations is a good example. The author also pointed out that local tax burden and urbanization development are the important ways to reduce the development differences and economic fluctuations in different regions. In fact, the effect of the fiscal decentralization system is not only related to its own attributes, but also has a great relationship with the implementation period and the region. In the article of "Regional Differences in Local Governmental Behaviors and Fiscal Decentralization Growth Effects," Wang Wenjian (2008) analyzed the panel data at the provincial level and concluded that in the eastern regions where the non-agricultural and non-state-owned economies are relatively developed, fiscal decentralization system is conducive to economic growth, while the results in central and western regions are on the contrary. Some scholars also think that before the implementation of the tax-sharing system, fiscal decentralization has no promotion effect on economic growth. However, the positive promotion effect after the tax-sharing system is very significant.

The impact of fiscal decentralization on economic development can also be explained by total factor productivity. In the article entitled "Fiscal Decentralization, Bank Credit and Total Factor Productivity," by analyzing the relationship between fiscal decentralization, bank credit and TFP, Wang Dingxiang (2011) divided TFP into technical efficiency index and technological progress index. Through the analysis of historical data, it is found that financial intervention by local governments (indicators of fiscal decentralization), endogenous and government-led exogenous financial credit will have both positive and negative effects on the improvement of total factor productivity. Through the research and analysis of provincial panel data, it was found that the reform of fiscal decentralization system promotes the increase of total factor productivity, endogenous financial credit has not become a positive factor to promote the improvement of total factor productivity, while the government-led exogenous financial credit has played a positive role in promoting total factor productivity.

The impact of fiscal decentralization on economic development is also reflected in the impact on poverty alleviation. In the article entitled "Fiscal Decentralization Favors Poverty - Evidence from the Inter-Dependent Tax Reform", Zhang Kezhong (2010) discussed the theoretical relationship between fiscal decentralization and poverty persistence. On one hand, regional competition, asymmetric information and the preference for homogeneity will cause fiscal decentralization to 
achieve the poverty reduction goal by increasing the allocation efficiency of pro-poor spending by local governments; on the other hand, fiscal decentralization aggravates the competition among local governments, which will distort the structure of public expenditure and at the same time, it will have a negative impact on the progress of poverty reduction targets. Therefore, the ultimate effect depends on the sum of the two effects, which depends on the degree of fiscal decentralization.

\section{Fiscal Decentralization and Government Control}

In the decentralized system, local government officials have more incentive to develop the local economy despite of the fact that the economic growth is at the price of serious pollution. In the article of "Does Chinese-style fiscal decentralization increase environmental pollution?", Wen Wenjuan and Zhong Maochu (2012) pointed out that decentralization of power under the fiscal decentralization system has led local governments to pay attention to regional public goods such as solid waste, yet take a free ride when providing global public goods (such as SO2 and wastewater). Local governments have adopted a relaxed management strategy for SO2 and solid pollutants in high-taxprofits industrial enterprises to increase fiscal revenues in the region and finally bring about a simultaneous increase in pollutant and sewage charges, which makes the control measures of collecting sewage charges to lower environmental costs useless.

In the article of "Perspectives on fiscal decentralization and environmental pollution: carbon emissions," Zhang Kezhong (2011) analyzed the relationship between fiscal decentralization and environmental pollution from the perspective of carbon emissions. Empirical study found that the degree of fiscal decentralization and per capita carbon emissions are positively correlated, and the degree of trade openness also has a negative impact on the reduction of carbon emissions. There are significant differences in the impact of fiscal decentralization on carbon emissions in different regions. In fact, the impact of fiscal decentralization on carbon emissions is mainly through the secondary and tertiary industries. This also shows that local governments ignore the carbon pollution due to improper incentive mechanism, and blindly pursue the status of economic benefits. In the article entitled "Competition for FDI, Refuge of Environment and Pollution - Reflecting on Chinese Decentralization," Chen Gang (2009) highlighted that under the background of fiscal decentralization, relaxing environmental regulation is an important means for local governments to compete with FDI. Local governments' "competition till the end" behavior also makes China a "pollution haven" for transnational polluting enterprises.

In fact, due to the aggravating environmental deterioration this year, the relationship between environmental protection and economic development has become a topic of public concern. In the article of "Environmental Protection and Economic Development under Chinese Decentralization," Pi Jiancai (2010) analyzed the relationship between environmental protection and economic development based on the Chinese decentralization system. The paper pointed out that the government's efforts will produce two kinds of effects: promotion of economic development and destruction of the local environment. When the government attaches more importance to environmental protection, the relationship between its efforts and economic development benefits changes.

\section{Conclusions}

The decentralization of China has had a significant impact on the country's political and economic life. The particularity of political centralization and fiscal decentralization in China has also caused many problems and contradictions to be solved urgently. To sum up, there are mainly two contradictions: the contradiction between the distribution of financial power and routine power and the contradiction between the interests of the promotion mechanism of officials with GDP as the core indicator. The mismatch between financial right and routine power makes local governments reduce their expenses and power by reducing extra-budgetary income and borrowing, and squeezing out the capital share of quasi-public goods with strong externalities such as compulsory education to reduce the contradictions brought by the mismatch; the contradiction between the interests of the promotion 
mechanism of officials with GDP as the core indicator can be embodied as the contradiction between the infrastructure and the development of science and education, and the conflict between the increase of government pro-poor spending under the fiscal decentralization and the distortion of the expenditure structure caused by government competition. In fact, the focus of the development of Chinese-style fiscal decentralization and the bottleneck that should be overcome nowadays are to solve these two major problems and contradictions.

In order to realize the relative balance between financial power and administrative power, it is necessary to establish a system of institutional mechanisms (collective selection mechanism, horizontal division of labor mechanism, vertical division of labor mechanism and contractual mechanism), financial and property mechanisms (collective selection mechanism, vertical allocation mechanism and legal supervision mechanism) and financial mechanism (collective selection mechanism, horizontal transfer mechanism, vertical transfer mechanism, legal supervision mechanism) to achieve the match between the two. To resolve the conflict of interest under the GDP index competition system, it is necessary to formulate the bottom line standard of basic public services and include them in the responsibility list of local governments, improve the accountability mechanism from bottom to top, enhance people's awareness of service, improve public service capabilities, and strengthen discipline inspection authorities at the same level. At the same time, it is also required to strengthen the same level discipline inspection organs, procuratorial organs, the people's Congress, the judiciary to local government accountability mechanism, enhance lateral accountability, improve cadre assessment and government performance evaluation system, and to improve public satisfaction in the examination and evaluation accounted for a large proportion.

\section{References}

[1] XU Yong-sheng, QIAO Bao-yun. Measurement of Fiscal Decentralization: Theory and Empirical Analysis of China from 1985 to 2007 [J].

[2] Gong Feng, Lei Xin. Quantitative measurement of Chinese-style fiscal decentralization [J] .Statistical Analysis, 2010,27 (10): 47-55.

[3] Tang Yugang, Chen Qiang. Decentralization, Land Finance and Urban Infrastructure [J] .Comparison of Economic and Social Systems, 2012 (06): 98-110.

[4] Gong Feng, Lu Hongyou.Public Expenditure Structure, Preference Matching and Fiscal Decentralization [J] .Management World, 2009 (01): 10-21.

Journal of Shandong University (Philosophy and Social Science), 2010 (05): 34-46. [5] Li Qiyun, Liu Xiaoyong. An Empirical Study on Equalization of Fiscal Decentralization, Transfer Payment and Regional Public Health Services [J]

[6] Fu Yong, Zhang Yan. Chinese decentralization and fiscal expenditure structure bias: the cost of competition for growth [J] .Managing the World, 2007 (03): 4-12 + 22.

[7] Fan Yunqi, Wang Wenju. Local fiscal expenditure preference analysis under the Chinese-style fiscal decentralization [J] .Journal of Economics and Management, 2010 (07): 40-47.

Shen Kunrong, Fu Wenlin.China's Fiscal Decentralization and Regional Economic Growth [J] .Management World, 2005 (01): 31-39 + 171-172.

[9] Zhou Yean, Zhang Quan.Fiscal decentralization, economic growth and volatility [J] .Management World, 2008 (03): 6-15 + 186.

[10] Wang Dingxiang, Liu Jie, Li Lingli.Fiscal decentralization, bank credit and total factor productivity [J] .Journal of Finance and Economics, 2011,37 (04): 69-79. 
Journal of Quantitative \& Technical Economics and Economics, 2010,27 (12): 3-15 (in Chinese) Zhang Kezhong, Feng Juncheng, Lu Yuanping. While fiscal decentralization contributes to the reduction of poverty? --Study on the inter-provincial evidence after the reform of tax sharing system $[\mathrm{J}]$.

[12] Yan Wenjuan, Zhongmao Chu. Chinese-style fiscal decentralization will increase environmental pollution? [J]. Finance and Economics, 2012 (03): 32-37.

[13] Zhang Kezhong, Wang Juan, Cui Xiaoyong. Fiscal Decentralization and Environmental Pollution: A Perspective of Carbon Emissions [J]. China Industrial Economics, 2011 (10): 65-75.

[14] CHEN Gang .FDI competition, environmental regulation and pollution shelter - Reflections on Chinese decentralization [J]. World Economic Research, 2009 (06): 3-7 + $43+87$.

[15] Pi Jiansai. Environmental Protection and Economic Development under Chinese Decentralization $[\mathrm{J}]$.Proceedings of Finance and Economics, 2010 (06): 10-14.

[16] WANG Wen-Jian, QIN Cheng-Lin.Regional Differences in Local Governmental Behaviors and Fiscal Decentralization Growth Effects: Judgments, Hypotheses and Tests Based on Empirical Analysis [J] .Management World, 2008 (01): 9-21.

[17] SUN Jian-fei, YUAN Yi. Fiscal Decentralization, Land Finance and China's Urban Expansion An Empirical Analysis Based on Simultaneous Equations Econometric Models [J] .Shanghai Economic Research, 2014 (12): 50-59 + 89.

[18] Wu Qun and Li Yongle. Fiscal Decentralization, Local Government Competition and Land Finance [J]. Finance and Trade Economics, 2010 (07): 51-59.

[19] The fundamental institutions of China's reforms and development. Journal of Economic Literature, 49(4), 1076-1151. 